\title{
EL PRINCIPIO AUTONÓMICO EN EL TEXTO CONSTITUCIONAL BOLIVIANO DE 2008
}

\author{
CAYETANO NÚÑEZ RIVERO \\ Profesor Titular de Derecho Constitucional \\ UNED
}

\author{
SUMARIO \\ I. Introducción. \\ II. Características y Principios del Estado \\ Autonómico boliviano. \\ III. Naturaleza jurídica del Estado Autonó- \\ mico. \\ IV. Características.
}

\section{INTRODUCCIÓN}

El principio descentralizador y autonómico recogido en el texto constitucional boliviano de 2008, se proclama desde el primer artículo del mismo, ocupando un lugar prominente en el Título I de la Constitución, dentro de la definición de las Bases Fundamentales del Estado y del Modelo del mismo. Ejemplo de la importancia concedida al tema en el nuevo texto constitucional, es que se inserta en el mismo artículo en que se proclama la entidad soberana del Estado, así como las características de éste, en cuanto Estado Social de Derecho, que tiene en su base el principio de la pluralidad, que no circunscribe sólo al ámbito político, sino que abarca igualmente los campos económico, jurídico, cultural y lingüístico; destaca igualmente que dicha proclamación se lleva a cabo tras definir el carácter unitario del Estado ${ }^{1}$, lo que

1 Artículo 1. Bolivia se constituye en un Estado Unitario Social de Derecho Plurinacional Comunitario, libre, independiente, soberano, democrático, intercultural, descentralizado y con autonomías. Bolivia se funda en la pluralidad y el pluralismo político, económico, jurídico, cultural y lingüistico, dentro del proceso integrador del país.

UNED. Teoria y Realidad Constitucional, núm. 24, 2009, pp. 565-584. 
implica la existencia de una sola soberanía en el Estado, que reside en la totalidad del pueblo boliviano ${ }^{2}$.

El principio autonómico se deriva del profuso reconocimiento que el texto hace desde su Preámbulo del hecho plurinacional del Estado, "(..) Asumimos el reto histórico de construir colectivamente el Estado Unitario Social de Derecho Plurinacional Comunitario (...)".

Sin embargo el principio autonómico manifestado en el texto boliviano, se diferencia de otros altamente descentralizados, como puede ser el español de 1978, que proclama el Estado de las Comunidades Autónomas o el italiano de 1947 que posibilita la conformación del Estado Regional y que son consecuencia del reconocimiento explícito en la Constitución de la existencia de nacionalidades (España) o regiones con elementos diferenciadores de otras del Estado (Italia), circunscritas a un ámbito territorial determinado, donde se posibilitan formas de autogobierno caracterizadas por la existencia de una autonomía de carácter no sólo administrativa, sino también política, pero cuyo hecho se deriva principalmente del reconocimiento constitucional del hecho diferenciador, aunque en un proceso posterior el principio descentralizador autonómico se haya extendido, como ocurre en el caso de España a la totalidad de las Regiones del Estado, transformadas actualmente en Comunidades y Ciudades Autónomas. Por el contrario en el caso boliviano, el reconocimiento autonómico hace mucho menos hincapié en el ámbito territorial que en el referente al reconocimiento de autogobierno de las naciones y pueblos originario campesinos; este hecho, que consideramos fundamental para el futuro mapa autonómico del Estado, se deriva del principio de que como indica el citado Preámbulo, el fin del texto constitucional es posibilitar la "refundación de Bolivia", debiendo entenderse esta refundación no sólo como un profundo cambio del Estado llevada a cabo mediante una amplia reforma de las estructuras e instituciones del mismo, sino que tiene un carácter de mayor profundidad, en cuanto que lo que "refunda" no se limita a la filosofía inspiradora del Estado y al aparato institucional del mismo, sino que incide en la propia refundación de uno de los elementos imprescindibles del Estado, como es la "Nación" ${ }^{3}$, ya que hasta el presente texto constitucional, que incorpora plenamente a los pueblos y naciones indígenas al concepto de nación boliviana, con lo que transforma el mismo concepto, dicho sector de la población, en su mayoría estuvo marginada de la actividad pública del Estado, de forma casi plena hasta las últimas décadas del pasado siglo. Con dicha afirmación no quiere sostenerse que la población indígena no fuera considerada en los diversos textos constitucionales como parte integrante de la población del Estado, lo que acontece desde la primera Carta Magna del

2 Artículo 7. Asímismo el artículo 3 define a la "nación " boliviana como la "conformada por la totalidad de las bolivianas y los bolivianos, las naciones y pueblos indigena originario campesinos, y las comunidades interculturales y afrobolivianas que en conjunto constituyen el pueblo boliviano",

3 Véase al respecto, NÚÑEZ RIVERO, C.; "Derecho Constitucional Comparado y Derecho Político iberoamericano"; Ed. Universitas, Madrid, 2002.pág.. 426. 
Estado $^{4}$, así como en los siguientes textos constitucionales, ${ }^{5}$ sino que por una parte, en virtud de los aspectos restrictivos incorporados al ejercicio de la soberanía nacional mediante el sufragio censitario y capacitario ${ }^{6}$, y por otra, el no considerar el principio de identidad diferenciada a este sector de la población, hacía que su incorporación se llevara a cabo en un aspecto, mediante el ejercicio de una ciudadanía restringida y en otro, en virtud de un proceso de "aculturación" ${ }^{7}$, ya que se efectuaba según los patrones culturales y jurídicos de la sociedad dominante en el país, de tal forma, que el reconocimiento de la nacionalidad boliviana a los miembros de las comunidades indígenas, debe considerarse de carácter individual y no implicaba incorporación al Estado de la concepción de sociedad que estas "Naciones" pudieran tener, tanto en sus acervos culturales como en la forma de organización institucional en su comunidad políticamente organizada ${ }^{8}$.

4 En la propia Acta de Independencia de seis de agoto de 1825, sólo hay una referencia y de carácter paternalista al elemento indígena, que nos lo presenta como algo aislado al proceso que estaba acaeciendo en el país y ajeno de todo protagonismo en el mismo "venid, en fin, y si cuando contempléis a nuestros hermanos indígenas, hijos del grande Manco Kapac, no se cubren vuestros ojos de torrentes de lágrimas, viendo en esos hombres los más desgraciados, esclavos tan bumillados, seres sacrificados a tantas clases de tormentos, ultrajes y penurias, diréis respecto de ellos parecerian los ilotas, ciudadanos de Esparta (...)

5 Como indica DURÁN BÖHME, J. C.; en el constitucionalismo del primer Estado de Derecho hispanoamericano, se impuso el principio de norma escrita y codificada, desarrollando el paradigma positivista tanto en el reconocimiento de las fuentes, como en la aplicación del Derecho, de tal forma, que el único origen legítimo y legalmente reconocido de creación de normas jurídicas era el Estado, así los sistemas jurídicos alternativos que, como los indígenas, habían recibido algún reconocimiento durante el periodo colonial fueron completamente desconocidos.; El Estatuto jurídico de los pueblos indigenas en la República de Bolivia: Una aproximación crítica desde el constitucionalismo", Univ. Complutense, Madrid,2006.

6 Ya desde el Decreto de convocatoria a Asamblea constituyente de 9 de febrero de 1825, que diera lugar al Acta de Independencia de seis de agosto de 1825, se ponía de manifiesto el sufragio censitario activo "El 25 de marzo se reunirán en la cabeza del partido la municipalidad, los notables y todo propietario de una renta de 300 pesos o poseedor de un oficio que se los produzca"(...), así como el pasivo "Para ser diputado se necesita ser mayor de 25 años y poseer una renta de 800 pesos anuales o tener un empleo, o ser profesor de alguna ciencia que se los produzca (...),

7 En el proceso de incorporación de las comunidades indígenas a las naciones hispanoamericanas, coincidimos con la clasificación que hace CABEDO MALLOL, V.; que distingue cuatro grandes periodos, uno primero correspondiente al periodo colonial, de carácter segregacionista, otro referente a los primeros tiempos de la República, que se caracteriza por un intento de asimilación, un tercero acaecido a mediados del siglo xx, de carácter integracionista, y uno más reciente, surgido en la última década del pasado siglo caracterizado por el reconocimiento del pluralismo nacional; "Constitucionalismo y Derecho Indígena en América Latina"; Univ. Politec. Valencia 2004, pág 83 y ss.

8 La conformación del primer Estado de Derecho en Bolivia, mediante el texto de 1826, se lleva a cabo siguiendo el modelo imperante en la época, que es el norteamericano y francés, que tiene en su base los principios de igualdad jurídica de los ciudadanos, así como los derechos y libertades individuales, sin considerar los derechos sociales o colectivos; así mismo, el nuevo sistema, al igual que otros Estados europeos e hispanoamericanos, se asentaba en el concepto de "Estado-Nación", que partía del principio de la homogeneidad cultural de sus ciudadanos, manifestada en el caso boliviano por la confesionalidad religiosa, como se pone de manifiesto en el artículo 6 de la Constitución de 1826; véase al respecto, NÚÑEZ RIVERO, C. y NÚÑEZ MARTÍNEZ, M.; "Iglesia y religión en los primeros textos constitucionales hispanoameri- 
El principio autonómico promulgado en el texto constitucional boliviano no se agota en el referente a la autonomía "indigena originaria campesina", concepto que utiliza la Constitución para referirse a las naciones y pueblos indígenas, a los que define como "Es nación y pueblo indígena originario campesino toda la colectividad bumana que comparta identidad cultural, idioma, tradición bistórica, instituciones, territorialidad y cosmovisión, cuya existencia es anterior a la invasión colonial española ${ }^{10}$, sino que abarca una pluralidad de sujetos autonómicos, de tal forma, que las entidades departamentales, regionales y municipales podrán también ser objeto de autonomía, aunque en unas la autonomía pueda considerarse de carácter político y administrativo y en otras sólo de carácter administrativo.

\section{CARACTERÍSTICAS Y PRINCIPIOS DEL ESTADO AUTONÓMICO BOLIVIANO}

La autonomía boliviana se caracteriza por los siguientes aspectos:

II.1. Se trata de un reconocimiento constitucional, tanto por la disposición jurídica en que se acoge, la "Norma Normarum", como por su contenido material. En este sentido, ya el Preámbulo de la propia Constitución proclama su voluntad de construir un Estado «(...) con respeto a la pluralidad económica, social, jurídica, política y cultural de los habitantes de esta tierra; (...) Asumimos el reto bistórico de construir colectivamente el Estado Unitario Social de Derecho Plurinacional Comunitario, que integra y articula los propósitos de avanzar hacia una Bolivia democrática, productiva, portadora e inspiradora de la paz, comprometida con el desarrollo integral y con la libre determinación de los pueblos". Así mismo, en el Título I de la Tercera parte Estructura y organización territorial del Estado, en el artículo 269, que encabeza el citado Título pormenoriza los sujetos autonómicos:

"1. Bolivia se organiza territorialmente en departamentos, provincias, municipios y territorios indígena originario campesinos. 2. La creación, mo-

canos: Virreinatos de Nueva Granada y Perú", Revista Nueva Época.n. ${ }^{\circ} 28$, págs 57-60, Universidad Libre. Bogotá. 2008. El concepto Estado-Nación se reforzaría especialmente en el nuevo Estado boliviano como consecuencia de la difícil delimitación territorial del país, en virtud de que grandes extensiones de su territorio habían pertenecido a diferentes virreinatos: Perú y Río de la Plata.

9 En contra de ciertos sectores de la doctrina que sostienen que el término " campesino", en el caso boliviano es inherente históricamente al de indígena, debemos destacar que esta categoría es de reciente aplicación y consecuencia de la Revolución de 1952 que posibilitó una amplia reforma agraria que entregó tierras a los indígenas, aunque casi siempre de forma individual, concediendo igualmente importantes derechos políticos, económicos y sociales, pues hasta ese momento, la gran mayoría de la población indígena trabajaban por cuenta ajena y no siempre en explotaciones agrarias.

10 Artículo 30. I.C.B. 
dificación y delimitación de las unidades territoriales se hará por voluntad democrática de sus habitantes, de acuerdo a las condiciones establecidas en la Constitución y la ley. 3. Las regiones formarán parte de la organización territorial, en los términos y las condiciones que determinen la ley". Así, como la posibilidad de acceder los mismos a la Autonomía «(..)Estos Departamentos podrán acceder a la autonomía departamental mediante referendo" ", "(...) La región podrá constituirse en autonomía regional, a iniciativa de los municipios que la integran, vía referendo en sus jurisdicciones. Sus competencias deben ser conferidas por dos tercios de votos del total de los miembros del órgano deliberativo departamental, ${ }^{12}$, (...) Son autonomias indigena originario campesinas los territorios indigena originario campesinos, y los municipios, y regiones que adoptan tal cualidad de acuerdo a lo establecido en esta Constitución y la ley. (... $)^{13}$.

II.2. Principio de constitucionalidad. No puede considerarse, stricto sen$s u$, un principio solamente autonómico, sino que es predicable de todas y cada una de las estructuras de instituciones que conforman el régimen político boliviano; la obligatoriedad para ciudadanos y poderes públicos de adecuar sus actividades al imperativo fijado en la Norma Fundamental. Su fundamento el artículo 410 "Todas las personas, naturales y jurídicas, así como los órganos públicos, funciones públicas e instituciones, se encuentran sometidos a la presente Constitución", que a su vez fija la jerarquía normativa en el Estado." (...) II. La Constitución es la norma suprema del ordenamiento jurídico boliviano y goza de primacía frente a cualquier otra disposición normativa. El bloque de constitucionalidad está integrado por los Tratados y Convenios internacionales en materia de Derechos Humanos y las normas de Derecho Comunitario, ratificados por el país. La aplicación de las normas jurídicas se regirá por la siguiente jerarquía, de acuerdo a las competencias de las entidades territoriales:

1. Constitución Política del Estado. 2. Los tratados internacionales. 3. Las leyes nacionales, los estatutos autonómicos, las cartas orgánicas y el resto de legislación departamental, municipal e indígena. 4. Los decretos, reglamentos y demás resoluciones emanadas de los órganos ejecutivos correspondientes"

Es por lo que los Estatutos Autonómicos, Cartas Orgánicas, transferencias y delegación competencial, deberán respetar el principio de jerarquía normativa debido a la Constitución, así como a la Ley Marco de Autonomías y Descentralización prevista en el texto constitucional, que regula el proceso para la elaboración de las normas indicadas ${ }^{14}$.

II.3. Principio de Unidad. Desde el preámbulo se proclama el sentido unitario del Estado, reafirmándose dicho concepto en lugar tan destacado como el artículo 1 'Bolivia se constituye en un Estado Unitario Social de De-

11 Artículo 274.C.B..

12 Artículo 280.III.C.B.

13 Artículo 291.C.B.

14 Artículo 271.CB. 
recho Plurinacional Comunitario, libre, independiente, soberano, democrático, intercultural, descentralizado y con autonomias. Bolivia se funda en la pluralidad y el pluralismo político, económico, jurídico, cultural y lingüístico, dentro del proceso integrador del pais". Así mismo, la proclamación de la soberanía es única para el Estado, residiendo en la totalidad del pueblo boliviano, y que nace de un poder constituyente único. "La soberanía reside en el pueblo boliviano, se ejerce de forma directa y delegada. De ella emanan, por delegación, las funciones y atribuciones de los órganos del poder público; es inalienable e imprescriptible "15.

No obstante, aunque el texto constitucional reconoce el derecho de "libre determinación y territorialidad" para las naciones y pueblos indígena originario campesino $^{16}$, éste queda anulado, o muy reducido, en cuanto supedita su ejercicio a lo establecido en la Constitución y la ley ${ }^{17}$, proclamando que aunque el autogobierno de las autonomías indígenas originario campesinas se ejercerá de acuerdo a sus normas, instituciones, autoridades y procedimientos, éste se llevará a cabo "en armonía con la Constitución y la ley»"18. De esta forma, para que pudiera cumplirse dicho derecho de determinación sería preciso que se produjera una promulgación de ley nacional específica que en todo caso iniciado el proyecto o recibido el mismo en el Senado, debería ser aprobada por la Asamblea Legislativa Plurinacional por mayoría absoluta de sus miembros presentes ${ }^{19}$. No obstante, lo indicado, debe manifestarse, que si la citada ley fuera objeto de recurso de inconstitucionalidad interpuesto por la Presidenta o Presidente de la República, Senadoras y Senadores, Diputadas y Diputados, Legisladores, Legisladoras y máximas autoridades ejecutivas de las entidades territoriales autónomas ${ }^{20}$, será el Tribunal Constitucional Plurinacional el encargado de resolver sobre dicha inconstitucionalidad, pudiendo declarar nula dicha ley por no estar acorde con la Constitución, sin que dicha sentencia pueda recurrirse ante otro órgano o institución del Estado ${ }^{21}$. De esta forma, se pone de manifiesto que si el ejercicio del derecho de "libre determinación" por parte de las naciones y pueblos indígena originario campesino, implicara un deseo de secesión del Estado boliviano o cualquier aspecto que a juicio del citado Tribunal Constitucional Plurinacional implicara una falta de armonía con la Constitución y leyes nacionales, éste no podría producirse en el marco actual de la Constitución, teniendo como única salida la posibilidad de Reforma Constitucional. Así mismo, debe indicarse que no solamente en los aspectos indicados anteriormente es precisa la consulta al Tribunal Constitucional Plurinacional, sino que también son "obligatorias las consultas de las autoridades

15 Artículo 7.CB..

16 Artículos 30.II.4. y 289.

17 Artículo 291.I.

18 Artículo 290.II.

19 Artículo 163.6.C.B.

20 Artículo 202.1.

21 Artículo 203.C.B. 
indigenas originario campesinas sobre la aplicación de sus normas jurídicas aplicadas a caso concreto" 22 .

II.4 Principio de igualdad. Parte del principio de la igualdad y sometimiento de todos los ciudadanos bolivianos ante la Ley. La igualdad jurídica básica de los ciudadanos se proclama ampliamente en el Título II del texto constitucional, correspondiente a los Derechos Fundamentales y sus garantías, sin que ello sea obstáculo para el reconocimiento de otros derechos proclamados específicos sólo aplicables a determinados colectivos de la población, como es el caso de las personas pertenecientes a las naciones y pueblo originario indígenas o afrobolivianos o de una determinada entidad departamental descentralizada, que a su vez puedan ser proclamados en el Estatuto o Carta Orgánica correspondiente. La igualdad de derechos y obligaciones en cualquier parte del territorio del Estado se vincula con lo dispuesto en el artículo 298, que preceptúa la competencia básica del Estado en la regulación de de las condiciones básicas que garanticen el ejercicio de los derechos y el cumplimiento de los deberes constitucionales. En virtud del artículo 270, el principio de igualdad rige la organización territorial y las entidades territoriales descentralizadas y autónomas. La igualdad jurídica básica de los departamentos se manifiesta en cuanto les corresponde a todos la misma representación en el Senado ${ }^{23}$.

Las entidades territoriales autónomas no estarán subordinadas entre sí y tendrán igual rango constitucional ${ }^{24}$.

\section{NATURALEZA JURÍDICA DEL ESTADO AUTONÓMICO}

\section{III.1. CARÁCTER CONSTITUCIONAL Y TIPOLOGÍA}

La naturaleza jurídica del Estado Autonómico boliviano es de carácter constitucional, en cuanto debe su existencia al texto constitucional, quien la crea ex novo, aunque en el caso de las naciones y pueblo indígena originario se invoquen razones de índole histórica ${ }^{25}$.

22 Artículo 202.8.C.B.

23 El Senado se compone de 36 miembros, correspondiendo cuatro senadores por Departamento. (art. 148.I y II).C.B.

24 Artículo 276.C.B.

25 A este respecto, el artículo 2 del texto constitucional, proclama "Dada la existencia precolonial de las naciones y pueblos indigena originario campesinos y su dominio ancestral sobre sus territorios, se garantiza su libre determinación en el marco de la unidad del Estado, que consiste en su derecho a la autonomía, al autogobierno, a su cultura, al reconocimiento de sus instituciones y a la consolidación de sus entidades territoriales, conforme a esta Constitución y la ley", de donde podría deducirse, sin perjuicio de lo que en párrafo posterior comentemos al respecto, que la autonomía para las naciones y pueblos indígena originario campesinos no es consecuencia de concesión estatal proclamada en la Constitución, sino previa al texto y aún al Estado, de tal forma, que éste simplemente se limita a reconocerla; no obstante, en todo caso, y bajo un punto de vista estrictamente jurídico debe resaltarse, que lo que la Constitución aporta fundamentalmente es el derecho a ejercitar dicha autonomía. 
No puede hablarse de una ordenación jurídica única de la autonomía, así el texto constitucional, en primer lugar proclama los derechos de las naciones y pueblos indígena originario campesinos al autogobierno ${ }^{26}$ y al reconocimiento de sus instituciones históricas de gobierno como parte de la estructura general del Estado. Se trata de una Autonomía de carácter política, en cuanto implica "el autogobierno como ejercicio de la libre determinación de las naciones y los pueblos originario campesinos, cuya población comparte territorio, cultura, historia lenguas, y organizaciones o instituciones jurídicas, políticas, sociales y económicas propias ${ }^{27}$. El concepto de autonomía política se refuerza en cuanto que el autogobierno se ejercerá en estos territorios mediante sus propias normas, instituciones, autoridades y procedimientos ${ }^{28}$ se trata por tanto de una autonomía que goza de instituciones de gobierno y capacidad de legislar en las materias sobre las que tiene competencia en su ámbito territorial.

Respecto a las restantes autonomías que consideramos de carácter política, debe destacarse la Departamental, que ya cuenta con los precedentes de los Departamentos de Santa Cruz, Beni, Pando y Tarija, aunque el texto constitucional no es nada prolijo al respecto, debe entenderse, como consecuencia del artículo 272, que aunque no menciona a los departamentos, sólo es aplicable a éstos y a los territorios de las naciones y pueblos indígena originario campesinos, "La autonomía implica la elección directa de sus autoridades por las ciudadanas y los ciudadanos, la administración de sus recursos económicos, y el ejercicio de las facultades legislativa, reglamentaria, fiscalizadora y ejecutiva, por sus órganos del gobierno autónomo en el ámbito de su jurisdicción y competencias y atribuciones".

Los Departamentos, entre los que se encuentran los actualmente descentralizados, cuyo hecho se reconoce por el propio texto constitucional ${ }^{29}$, cuentan con un órgano ejecutivo, que en principio reproduce el sistema presidencialista ${ }^{30}$, "El órgano ejecutivo departamental está dirigido por la Gobernadora o el Gobernador, en condición de máxima autoridad ejecutiva ${ }^{31}$. Aunque no se indica en el texto ni la forma de elección del titular del órgano ejecutivo, ni la duración de su mandato, parece deducirse del artículo $274^{32}$, así como por analogía con el Presidente de la República, según el artículo 166 I ${ }^{33}$ y por

26 Artículos 30 y 31 C.B.

27 Artículo 289.C.B.

28 Artículo 290.IIC.B.

29 Transitoria Tercera I y II.

30 Debemos entender que el carácter presidencialista en el ámbito departamental es más marcado que en el estatal, en cuanto que en este último, en virtud del artículo 165 se define el Órgano Ejecutivo como el compuesto por "la Presidenta o el Presidente del Estado, la Vicepresidenta o el Vicepresidente del Estado, y las Ministras y los Ministros del Estado".

31 Artículo 279.C.B.

32 “...) En los departamentos descentralizados se efectuará la elección de prefectos y consejeros departamentales mediante sufragio universal (...)"

33 "La Presidenta o el Presidente y la Vicepresidenta o el Vicepresidente del Estado serán elegidas o elegidos por sufragio universal, obligatorio, directo, libre y secreto. Será proclamada a la 
los Estatutos aprobados anteriormente por referéndum en julio de $2006^{34}$, que el gobernador sea elegido por voto universal, igual y directo ${ }^{35}$ y no de manera indirecta como acontece en el Estado Autonómico Español; respecto a la duración de su mandato debemos entender que será el propio Estatuto el que lo determine ${ }^{36}$.

Cuentan igualmente con una Asamblea Departamental, con facultad "deliberativa, fiscalizadora y legislativa ${ }^{37}$; respecto a su capacidad legislativa, ésta se derivará en su ámbito y competencia del contenido del Estatuto, aunque en todo caso, incluirá el desarrollo legislativo de las competencias exclusivas que el artículo 300 contiene, así como aquellas que les sean transferidas o delegadas ${ }^{38}$, o en su caso, compartidas con el Estado, cuyo desarrollo corresponde a las Autonomías Departamentales ${ }^{39}$.

Respecto a las autonomías de carácter administrativo y no político, cabe destacar en primer lugar las Autonomías Regionales, a las que la Constitución define ${ }^{40}$ como la "conformada por varios municipios o provincias con continuidad geográfica y sin trascender limites departamentales, que compartan cultura, lenguas, historia, economía y ecosistemas en cada departamento, se constituirá como un espacio de planificación y gestión ${ }^{41}$.

Las autonomías regionales se constituyen a iniciativa de los municipios que la integran, que deben pronunciarse vía referéndum en sus jurisdicciones. Cuenta con un Estatuto; Sus competencias les son conferidas por la Asamblea Departamental ${ }^{42}$. El texto constitucional no especifica las competencias de que goza, salvo al indicar que contará con una Asamblea Regional con facultad deliberativa, normativa-administrativa y fiscalizadora, en el ámbito de sus competencias ${ }^{43}$, así mismo, cuenta con un órgano ejecutivo.

Aunque la Constitución en su artículo 269 hace referencia a las Provincias como forma de organización territorial, en el resto del texto no se men-

Presidencia y a la Vicepresidencia la candidatura que haya reunido el cincuenta por ciento más uno de los votos válidos; o que haya obtenido un mínimo del cuarenta por ciento de los votos válidos, con una diferencia de al menos diez por ciento en relación con la segunda candidaturan.

34 Como se ha indicado anteriormente, estos estatutos precisan para estar en vigor adaptarse a la actual constitución.

35 Valga como ejemplo el artículo 28 del estatuto del departamento de Santa Cruz.

36 El texto constitucional referente a la Jefatura del Estado, proclama en su artículo 168, que "El periodo de mandato de la Presidenta o del Presidente y de la Vicepresidenta o del Vicepresidente del Estado es de cinco años, y pueden ser reelectas o reelectos por una sola vez de manera continua" mientras que el Estatuto de Santa Cruz, en el artículo anteriormente citado establece un periodo de cinco años, pudiendo ser reelecto por una sola vez en periodos discontinuos.

37 Artículo 277.C.B.

38 Artículo 330.II.C.B.

39 Artículo 297.I.d).C.B.

40 Artículo 280.I.C.B.

41 Excepcionalmente la región puede estar conformada por una sola provincia, que por sí sola tenga las características definidas para la Región. Igualmente, en los centros urbanos mayores a 500.000 habitantes podrán conformarse regiones metropolitanas.

42 Artículo 280.III.y artículo 301.C.B

43 Artículo 281,C.B. 
ciona que puedan ser objeto de autonomía, salvo en el caso de convertirse en Autonomía Regional y por supuesto como parte la Autonomía Departamental.

Respecto a la Autonomía Municipal, que podemos considerar la más antigua del país remontándose a los tiempos de la pertenencia del mismo a la Corona de España, es en donde se producen menos cambios respecto al texto constitucional anterior, salvo en lo referente al protagonismo otorgado a las naciones y pueblo originario campesino, respecto a su incardinación en los órganos del gobierno municipal ${ }^{44}$. El gobierno autónomo municipal está "constituido por un Concejo Municipal con facultad deliberativa, fiscalizadora y legislativa municipal en el ámbito de sus competencias; y un órgano ejecutivo, presidido por la Alcaldesa o el Alcalde ${ }^{45}$. El Concejo Municipal podrá elaborar el Proyecto de Carta Orgánica, que será aprobado siguiendo los mismos procedimientos indicados anteriormente para los otros supuestos autonómicos ${ }^{46}$. Los municipios cuentan con un amplio elenco de atribuciones exclusivas $^{47}$, que no agotan sus competencias, ya que puede recibir otras delegadas o transferidas ${ }^{48}$.

\section{III.2. Tiene en su base un solo Poder constituyente}

El texto constitucional de 2008 y la Asamblea Constituyente que lo elaboró eran consecuencia de la existencia previa de un Estado de carácter unitario y los constituyentes que componían la Asamblea eran representativos de la totalidad del pueblo boliviano y no de cada uno de los Departamentos o grupos étnicos presentes en el mismo. Así mismo, el texto fue sometido a referéndum de la totalidad del pueblo boliviano.

El texto resultante no es consecuencia de la existencia de entidades soberanas previas, que en un momento decidan fusionarse para crear una entidad unificada, lo que no obsta, para que pueda hablarse de una refundación del Estado y la nación como se ha indicado anteriormente, aunque como proclama el texto resultante existe un solo poder constituyente originario, que es el pueblo boliviano ${ }^{49}$. No puede hablarse de pactos entre entidades soberanas, ya que la soberanía, como proclama el texto constitucional es una cualidad exclusiva del Estado ${ }^{50}$.

44 En los municipios donde existan naciones o pueblos indígena originario campesinos, que no constituyan autonomía indígena originario campesina, éstos podrán elegir sus representantes ante el Concejo Municipal de forma directa mediante normas y procedimientos propios y de acuerdo a la Carta Orgánica Municipal. (Art.284 II).C.B.

45 Artículo 283.C.B.

46 Artículo 284.IV C.B.

47 Artículo 302.I.C.B.

48 Artículo 302.II.C.B

49 Artículo 7.C.B.

50 Artículo 1.C.B. 
Así mismo, la reforma constitucional, sea de carácter parcial, total, o que afecte a los derechos, deberes y garantías o a la primacía y reforma del texto, tiene que ser aprobada por la Asamblea Legislativa Plurinacional, en el caso de reforma parcial51, o por Asamblea Constituyente Originaria Plenipotenciaria elegida a tal efecto $^{52}$ y ser aprobada en ambos casos por referéndum constitucional del pueblo boliviano.

Cabe destacar igualmente, que la Ley Marco de Autonomías y Descentralización debe ser aprobada por la Asamblea Legislativa Plurinacional ${ }^{53}$ y que dicha Ley regulará el procedimiento para la elaboración de los Estatutos Autonómicos y Cartas Orgánicas la transferencia y delegación competencial, el régimen económico financiero, y la coordinación entre el nivel central y las entidades territoriales descentralizadas y autónomas ${ }^{54}$. Así mismo, los proyectos de Estatuto o Carta Orgánica deben pasar antes de su aprobación por un control previo de constitucionalidad ${ }^{55}$.

Ello no obsta, para que pueda reconocerse un amplio papel protagonista de las entidades descentralizadas, aunque siempre sujeto a la jerarquía normativa constitucional, en la conformación de la nueva organización territorial del Estado, aspecto que es perceptible en los orígenes de las mismas, " $L a$ creación, modificación y delimitación de las unidades territoriales se hará por voluntad democrática de sus habitantes, de acuerdo a las condiciones establecidas en la Constitución y la ley, ${ }^{56}$, como en la elaboración de sus Estatutos o Cartas Orgánicas,"Cada órgano deliberativo de las entidades territoriales elaborará de manera participativa el proyecto de Estatuto o Carta Orgánica que deberá ser aprobado por dos tercios del total de sus miembros, y previo control de constitucionalidad, entrará en vigencia como norma institucional básica de la entidad territorial mediante referendo aprobatorio en su jurisdicción "57. Así mismo, se percibe el protagonismo de las entidades autónomas en su capacidad ejecutiva respecto a las competencias que le atribuye el Estatuto, así como en las de carácter compartido ${ }^{58}$, concurrentes $^{59}$, e incluso privativas, si tal función fuera transferida por los órganos centrales del Estado $^{60}$; igualmente, tiene capacidad legislativa plena en las materias denominadas "exclusivas de los gobiernos departamentales" proclamadas en el artículo 300 del texto constitucional, así como en la legislación de desarrollo de las materias compartidas, aunque la legislación básica en este apartado corresponda a la Asamblea Legislativa Plurinacional ${ }^{61}$.

51 Artículo 411.II.C.B.

52 Artículo 411.I.C.B.

53 Artículo 271.II.C.B.

54 Artículo 271 I.C.B.

55 Artículo 275 I.C.B.

56 Artículo 269.II.C.B.

57 Artículo 275.C.B.

58 Artículo 297.I.d )C.B

59 Artículo 297.I.c) C.B.

60 Artículo 297.I.b) C.B

61 Artículo 297.Id).C.B. 


\section{CARACTERÍSTICAS}

\section{IV.1. ES UN PROCESO VOLUNTARIO Y ABIERTO}

A diferencia de otros modelos de Estados Compuestos donde la atribución de competencias es bien obligatoria, como acontece con los Estados Federales, bien discrecional, como en el supuesto de Portugal, el texto boliviano, al igual que el español, plantea un modelo de organización territorial, que tiene en su base el principio de voluntariedad, de tal forma, que la Constitución comprende la Autonomía no como una obligación, sino como un auténtico derecho.

De esta forma, con respecto a las naciones y pueblos indígena originario, dicho derecho se proclama en el artículo 2, reafirmándose el mismo en el artículo 30.II.4, en el que se añade el derecho de libre determinación y territorialidad $^{62}$; no obstante lo indicado, en parte alguna del texto se menciona la obligatoriedad de constituirse en entidad descentralizada, proclamando la Constitución que dicha autonomía se "constituirá por la voluntad expresada de su población en consulta en conformidad a sus normas y procedimientos propios como único requisito exigible. "63

Respecto a las restantes entidades que pueden ser objeto de descentralización, el texto constitucional se limita a proclamar tal derecho y a dejar la iniciativa de la misma a los territorios afectados ${ }^{64}$, "la creación, modificación $y$ delimitación de las unidades territoriales se hará por voluntad democrática de sus habitantes, de acuerdo a las condiciones establecidas en la Constitución y la ley".

Con respecto a los Departamentos que en julio de 2006, mediante referéndum aprobaron su autonomía y cuentan con un Estatuto Autonómico ${ }^{65}$, el texto constitucional reconoce, aún sin nombrar a ninguno de ellos, que se trata de entidades autonómicas, de tal forma, que en la transitoria Tercera I proclama que "accederán directamente al régimen de autonomías departamentales, de acuerdo con la Constitución", aunque no reconoce los actuales estatutos de los citados departamentos, ya que en la Transitoria II ordena que " deberán adecuar sus estatutos a esta Constitución y sujetarlos a control de constitucionalidad ${ }^{66}$.

Podemos indicar que es un proceso abierto y flexible, en cuanto que por una parte no existe límite en el tiempo para la configuración de entidades autonómicas, pudiendo iniciarse el proyecto autonómico o la reforma estatutaria del mismo en el momento que lo manifieste la población afectada. Así

62 Mediante el artículo 32, puede entenderse que este derecho se hace extensivo al "pueblo afroboliviano".

63 Artículo 293I.C.B.

64 Artículo 269.II.C.B.

65 Se trata de los Departamentos de Santa Cruz, Beni, Pando y Tarija.

66 Los actuales estatutos de los referidos departamentos, especialmente el de Santa Cruz, tienen una clara inspiración en el concepto de Estatuto Autonómico español.. 
mismo, la lista de competencias que pueden asumir las entidades autonómicas no responden a una estructuración monolítica y cerrada, sino que por el contrario, se expresan de una manera elástica dentro del juego competencial de los artículos 297, 298, 299 y 300 de la Constitución, especialmente en el caso de las autonomías de naciones y pueblos indígena originario, en virtud de los ambiguos principios proclamados en el artículo 30.II y en el rango reconocido por la Constitución a los Tratados internacionales, entre los que debe destacarse el Convenio 169 de la OIT $^{67}$ y la Declaración de Naciones Unidas sobre Derechos de los Pueblos indígenas ${ }^{68}$ que afectan de manera directa al autogobierno y territorialidad de las comunidades indígenas ${ }^{69}$. En este aspecto, debe resaltarse el carácter de naturaleza abierta, en virtud de que deberá ser la jurisprudencia del Tribunal Constitucional Plurinacional, en un proceso similar a lo realizado por el Tribunal Constitucional de Colombia, quien delimite la aplicación de los principios constitucionales y los tratados y convenios internacionales ante los posibles y más que probables conflictos que se presenten respecto a la autonomía de las comunidades indígenas.

No puede hablarse tampoco de que el hecho autonómico en Bolivia tenga un carácter uniforme, pues ya desde el propio texto constitucional marca claras diferencia en el terreno de los principios entre el correspondiente a las autonomías de naciones y pueblos indígena originario ${ }^{70}$ y el referente a las autonomías departamentales ${ }^{71}$. En todo caso, corresponde a la población de cada entidad descentralizada el contenido de cada Estatuto, así como a la voluntad de la Asamblea Legislativa Plurinacional.

\section{IV.2. Un MODELO DE ESTADO INDEFINIDO Y NUEVO}

En el primer epígrafe del presente trabajo se ha hecho referencia a las profundas diferencias existentes entre el modelo boliviano que proclama el texto constitucional y otros casos de Estados Compuestos, como es el caso de los Estados Federales, el Estado Regional o el Estado de las Comunidades Autónomas, nos encontramos por tanto ante un modelo nuevo, cuya diferencia con los anteriormente indicados, en la opinión que sostenemos, no se deriva tanto de la diferencia de atribuciones que puedan detentar las entidades descentralizadas y su mayor o menor capacidad para ejercer los principios de Autonomía Política, sino fundamentalmente en uno de los sujetos

67 El Convenio fue aprobado en la OIT el 27 de junio de 1989 y fue ratificado por el Congreso boliviano el 11 de julio de 1991. Ley. N. ${ }^{\circ} 1257$.

68 Ratificada por Ley N. 3760 de 7 de noviembre de 2007.

69 Especialmente los artículos, 6,7,y 8 del citado Convenio.

70 Véase el Capítulo IV"Derechos de las naciones y pueblos indigenas originario campesinos", del Título II, "Derechos Fundamentales y Garantías", así como el Capítulo VII "Autonomía indigena originaria campesina"del Títilo I "Estructura y organización territorial del Estado"..

71 Capítulo II "Autonomía Departamental" del Título I"Estructura y organización territorial del Estado. 
objeto de descentralización., que en el caso boliviano incluye a las naciones y pueblos indígena originario campesino.

Sobre este punto deben hacerse las siguientes reflexiones:

a) Mientras que la Autonomía Departamental tiene un techo definido, consistente en el número de Departamentos existentes: nueve, la posible autonomía indígena originaria campesina, carece de este límite, así como indica el artículo 291.I ". Son autonomías indigena originario campesinas los territorios indigena originario campesinos, y los municipios, y regiones que adoptan tal cualidad de acuerdo a lo establecido en esta Constitución y la ley".De esta forma el posible número de entidades y el tamaño de las mismas se nos muestra de carácter indeterminado, dependiendo sólo de la ambigua proclamación del artículo 289, "La autonomía indigena originaria campesina consiste en el autogobierno como ejercicio de la libre determinación de las naciones y los pueblos indígena originario campesinos, cuya población comparte territorio, cultura, bistoria, lenguas, y organización o instituciones jurídicas, politicas, sociales y económicas propias", que al igual que el artículo $290 . \mathrm{I}^{72}$, no indica concretamente el territorio objeto de descentralización ni el ámbito del mismo, dejando tal consideración a la libre voluntad de la comunidad indígena que habite un determinado territorio; a este respecto, el texto constitucional, sólo establece una cláusula restrictiva en el artículo 293.3, "La Ley establecerá requisitos mínimos de población y otros diferenciados para la constitución de autonomía indigena originario campesina ", que en la opinión que sostenemos, lo único que manifiesta es que la constitución de una autonomía indígena originaria campesina puede estar sujeta a que la misma esté compuesta por un determinado número poblacional, pero que no impide, pues en lugar alguno del texto lo proclama, que la población indígena, escasa en un territorio no pueda unirse a otras comunidades indígenas con el fin de conformar una autonomía indígena originaria campesina.; de hecho el artículo 291.II, es claro al respecto, "Dos o más pueblos indigenas originarios campesinos podrán conformar una sola autonomía indigena originaria campesina", aunque este hecho esté sujeto al principio de legalidad "Para constituir una autonomía indigena originario campesina cuyos territorios se encuentren en uno o más municipios, la ley señalará los mecanismos de articulación, coordinación y cooperación para el ejercicio de su gobierno" ${ }^{73}$.

Se puede argumentar en contra de lo indicado, que posiblemente en el espíritu del constituyente se asentaba la idea de que la agrupación de comunidades indígenas para conformar entidades más amplias, estuviera reservado a entidades limítrofes, como así parece poner de manifiesto el artículo 294.III, "En los municipios donde existan comunidades campesinas con estructuras orga-

72 "La conformación de la autonomía indigena originario campesina se basa en los territorios ancestrales, actualmente habitados por esos pueblos y naciones, y en la voluntad de su población, expresada en consulta, de acuerdo a la Constitución y la ley".

73 Artículo 293.IV.C.B. 
nizativas propias que las articulen y con continuidad geográfica, podrá conformarse un nuevo municipio, siguiendo el procedimiento ante la Asamblea Legislativa Plurinacional para su aprobación, previo cumplimiento de requisitos y condiciones conforme a la Constitución y la ley.", y que además este reconocimiento estaba reservado para el tipo de Autonomía Municipal, o bien de carácter Regional ${ }^{74}$; sin embargo, ha de hacerse constar, que en lugar alguno de la Constitución se proclama tal necesidad de proximidad geográfica, por otra parte, no debe olvidarse, que en el caso de las autonomías regionales y municipales reguladas en los capítulos Tercero y Cuarto de la Estructura y organización Territorial del Estado $^{75}$, éstas se consideran como autonomías de carácter Administrativo y no Políticas, mientras que en el caso de las Autonomías Indígena Originaria Campesina, éstas deben tener la consideración de Autonomías Políticas, y ello, independientemente de su ámbito territorial, tanto por ser uno de los principios constitucionales, como por el amplio elenco de atribuciones que les otorga el texto constitucional $^{76}$, a lo que debemos unir los Tratados y Convenios internacionales, firmados por el Estado boliviano, especialmente el convenio $169^{77}$ de la $\mathrm{OIT}^{78}$, antes citado, sin olvidar que el propio texto constitucional, en el artículo 410, incluye a dichos tratados en el "bloque de constitucionalidad."79

b) La difícil caracterización de las Autonomías Indígena Originaria Campesina.

En epígrafe anterior hemos indicado la dificultad de incluir las Autonomías Indígena Originaria Campesina como entidad descentralizada de ámbito territorial, pues aunque indudablemente se asienta sobre un territorio, el que habita la nación o comunidad indígena determinada, la amplitud del mismo no es requisito imprescindible para el ejercicio del derecho de Autonomía Política.; afirmación que puede sostenerse, en virtud de la definición que el texto constitucional proporciona de lo que se entiende por dicha autonomía "La autonomía indigena originaria campesina consiste en el autogobierno como ejercicio de la libre determinación de las naciones y los pueblos indigena originario campesinos, cuya población comparte territorio, cultura, bistoria, lenguas, y organización o instituciones jurídicas, politicas, sociales y económicas propias. ${ }^{80}$ Así mismo, en el texto no se ponen restricciones al ámbito territorial, proclamando incluso la posibilidad de que se trate de un solo municipio, sin que por ello, quede afectado el concepto, "Son autono-

74 Artículo 295.II.C.B.

75 La Autonomía Regional se trata en los artículos 280 a 282 y la Municipal en los 283 y 284.

76 Artículos 289 a 296 y 303305

77 El artículo 257.I, proclama que "Los tratados internacionales ratificados forman parte del ordenamiento jurídico interno con rango de ley".

78 Debe tenerse en cuenta igualmente, que diversos artículos del citado convenio han sido convertidos en norma interna, en virtud de que el nuevo texto ha reproducido en su contenido varios de ellos.

79 El concepto de bloque de constitucionalidad en el constitucionalismo boliviano debe considerarse más próximo a la doctrina francesa al respecto que a la española.

80 Artículo 289.I. C.B.. 
mías indigena originario campesinas los territorios indígena originario campesinos, y los municipios, y regiones que adoptan tal cualidad de acuerdo a lo establecido en esta Constitución y la ley ${ }^{81}$.

No obstante lo indicado, el texto en el artículo 302.II se refiere a la existencia de regiones indígenas originario campesinas, aunque como hace respecto a las restantes regiones se limita a proclamar que asumirán las competencias que les sean transferidas o delegadas, sin proceder a enumerarlas, competencias que para la Autonomía indígena originario campesina, sin definir su ámbito territorial, sí efectúa mediante un amplio elenco de atribuciones y competencias en el artículo 304, refiriéndose a las exclusivas (304.I), compartidas (304.II) y concurrentes (304.III). Competencias, a las que entendemos habría que añadir las correspondientes al ámbito territorial de que se trate y proclamadas en e texto constitucional con carácter general.

De las competencias atribuidas a las Autonomías indígenas originario campesinas, procede en el objeto del presente trabajo, destacar tres que no figuran en las restantes Autonomías proclamadas en el texto constitucional, así nos referimos a dos competencias exclusivas: a) Ejercicio de la jurisdicción indígena originario campesina para la aplicación de justicia y resolución de conflictos a través de normas y procedimientos propios de acuerdo a la Constitución y la ley ${ }^{82}$, b) Participar, desarrollar y ejecutar los mecanismos de consulta previa, libre e informada relativos a la aplicación de medidas legislativas, ejecutivas y administrativas que los afecten ${ }^{83}$ y a una competencia compartida, c) Intercambios internacionales en el marco de la política exterior del Estado.

Respecto a la primera indicada Ejercicio de la jurisdicción indígena originario campesina para la aplicación de justicia y resolución de conflictos a través de normas y procedimientos propios de acuerdo a la Constitución y la ley. Como indica el texto constitucional la jurisdicción indígena originario campesina se fundamenta en un vínculo particular de las personas que son miembros de la respectiva nación o pueblo indígena originario campesino ${ }^{84}$. No obstante, cabe destacar, que el artículo 179, en su primer párrafo, proclama que la función judicial es única, así como el artículo 298. II. 24, que hace lo propio respecto a la Administración de Justicia a la que sitúa como competencia exclusiva del nivel central del Estado, en el mismo sentido, el citado artículo 179. IV, proclama que el Consejo Nacional de la Magistratura es parte del Órgano Judicial ${ }^{85}$, de donde podría deducirse, que la existencia de Tribunales Departamentales sólo responde a una relación territorial que deri-

81 Artículo 291. C.B.

82 Artículo 304.8. C.B.

83 Artículo 304. 21 C.B.

84 Artículo 191.I C.B.

85 El Consejo de la Magistratura es la instancia responsable del régimen disciplinario de la jurisdicción ordinaria, agroambiental y de las jurisdicciones especializadas; del control y fiscalización de su manejo administrativo y financiero; y de la formulación de políticas de su gestión. Art. 193. 
va del lugar de su sede, y que las competencias de de los órganos jurisdiccionales continúan siendo competencia del órgano judicial único existente en el Estado, avala dicha afirmación la existencia de un solo Tribunal Supremo de Justicia, al que el artículo 181, define como el máximo tribunal de la jurisdicción ordinaria; otro tanto ocurre con la jurisdicción agroambiental, donde el Tribunal Agroambiental es el máximo tribunal especializado de dicha jurisdicción ${ }^{86}$.

Sin embargo, el citado artículo 179, introduce en párrafo posterior la existencia de "la jurisdicción indigena originaria campesina" ${ }^{87}$, que proclama "se ejerce por sus propias autoridades", añadiendo que "la jurisdicción ordinaria y la jurisdicción originario campesina gozarán de igual jerarquía”.En principio si nos atenemos a lo proclamado en el citado artículo no parece que se rompiera el principio de unidad de la función judicial, sólo cambiaría la autoridad judicial, sin embargo, en el artículo 190, se proclama que no sólo ésta resulta afectada, sino también los principios a aplicar, valores culturales, normas y procedimientos, a lo que el texto sólo pone el límite del derecho a la vida, defensa y demás derechos y garantías proclamados en la Constitución ${ }^{88}$.

La jurisdicción indígena originario campesina se ejerce en los siguientes ámbitos de vigencia personal, material y territorial ${ }^{89}$.

a) Están sujetos a esta jurisdicción los miembros de la nación o pueblo indígena originario campesino, sea que actúen como actores o demandado, denunciantes o querellantes, denunciados o imputados, recurrentes o recurridos.

b) Conoce los asuntos indígena originario campesino de conformidad a lo establecido en una Ley de Deslinde Jurisdiccional.

c) Se aplica a las relaciones y hechos jurídicos que se realizan o cuyos efectos se producen dentro de la jurisdicción de un pueblo indígena originario campesino.

Las decisiones de la jurisdicción originaria campesina son de obligado cumplimiento para las personas y autoridades públicas y corresponde al Estado asegurar el mismo, así como su fortalecimiento ${ }^{90}$.

La Constitución prevé la existencia de una Ley de Deslinde Jurisdiccio-

86 Artículo 186. C.B.

87 De esta forma, se desarrolla el derecho proclamado en el artículo 30.II.5, referente a que las instituciones de las naciones y pueblos indígena originario sean parte de la estructura general del Estado, y 14, referente al ejercicio de su sistema jurídico acorde a su cosmovisión.

88 "I.Las naciones y pueblos indigena originario campesinos ejercerán sus funciones jurisdiccionales y de competencia a través de sus autoridades, y aplicarán sus principios, valores culturales, normas y procedimientos propios. II. La jurisdicción indigena originaria campesina respeta el derecho a la vida, el derecho a la defensa y demás derechos y garantías establecidos en la presente Constitución.. Art.190.C:B.

89 Artículo 191.II. C.B.

90 Artículo 192.C.B. 
nal, que determine los mecanismos de coordinación y cooperación entre la jurisdicción indígena originaria campesina con la jurisdicción ordinaria y la jurisdicción agroambiental y todas las jurisdicciones constitucionalmente reconocidas $^{91}$ En dicha Ley deberían delimitarse con mucha menos ambigüedad que en el texto constitucional las competencias materiales, personales y territoriales de cada una de las jurisdicciones, así como la aplicación y alcance de los principios derivados de los tratados y convenios internacionales sobre los pueblos indígenas suscritos por el Estado boliviano, que ya algún sector de la doctrina califica de rango "supraconstitucional".

Así mismo, la Constitución en previsión de conflictos de competencia entre la jurisdicción indígena originara campesina y la jurisdicción ordinaria y agroambiental, proclama que el Tribunal Constitucional Plurinacional ${ }^{92} \mathrm{CO}^{-}$ nocerá y resolverá sobre los mismos ${ }^{93}$.

Sobre la segunda competencia a que nos referimos anteriormente Participar, desarrollar y ejecutar los mecanismos de consulta previa, libre e informada relativos a la aplicación de medidas legislativas, ejecutivas y administrativas que los afecten, puede considerarse una consecuencia de los Derechos de las Naciones y Pueblos Indígena Originario, contenidos en el artículo 30 del texto constitucional, "En el marco de la unidad del Estado y de acuerdo con esta Constitución las naciones y pueblos indigena originario campesinos gozan de los siguientes derechos(...) A ser consultados mediante procedimientos apropiados, y en particular a través de sus instituciones, cada vez que se prevean medidas legislativas o administrativas susceptibles de afectarles. En este marco, se respetará y garantizará el derecho a la consulta previa obligatoria, realizada por el Estado, de buena fe y concertada, respecto a la explotación de los recursos naturales no renovables en el territorio que babitan ${ }^{94}$, que reproduce casi íntegramente el artículo 6. ${ }^{\circ}$ a) del Convenio 169 de la OIT, y varios preceptos de la declaración de las Naciones Unidas sobre los derechos de los pueblos indígenas ${ }^{95}$. En la misma línea, referente a la explotación de la riqueza nacional, se mantiene el principio de consulta a la población afectada en el territorio objeto de explotación, así, aún cuando el Estado proclama la propiedad de la misma y su administración ${ }^{96}$, reitera la necesidad de consulta a la población afectada ${ }^{97}$.

Sobre este punto, lo que queda por delimitar es si la consulta que debe realizar el Estado, que entendemos es obligatoria, si así lo solicita la comunidad afectada, tiene un mero carácter consultivo, o por el contrario es vinculan-

91 Artículo 192.III. C.B.

92 Los miembros del Tribunal Constitucional Plurinacional serán elegidos con criterios de plurinacionalidad, con representación del sistema ordinario y del sistema indígena originario campesino. (art. 197.I).

93 Artículo 202.11.

94 Artículo 30.II. 15.

95 Artículos 3,5,18,19,20,26 y 27.

96 Artículos 311.2 y 349.I.C.B.

97 Artículo 352. C.B. 
te. A este respecto, si nos atenemos a lo dispuesto en los tratados y convenios internacionales, que como se indicó anteriormente forman parte del bloque de constitucionalidad y son norma interna, se imposibilitaría toda acción de gobierno contraria a las decisiones de la comunidad afectada ${ }^{98}$, salvo en interpretación del Tribunal Constitucional Plurinacional, a favor del principio de función social de la propiedad y los intereses del Estado ${ }^{99}$, posibilitando otro tipo de compensaciones, de acuerdo con lo proclamado en el artículo 30.II.16.

Sobre la tercera competencia señalada anteriormente, Intercambios internacionales en el marco de la política exterior del Estado, el artículo 255, referente a las relaciones internacionales del Estado, proclama que los mismos, entre otros principios se regirán por el «respeto a los derechos de los pueblos indígenas originarios campesinos", manifestación que se complementa con el principio contenido en el artículo 265.II, "El estado fortalecerá la integración de sus naciones y pueblos indigenas originario campesino con los pueblos indigenas del mundo". Sobre este punto, en la opinión que sostenemos, además de la colaboración que el Estado debe propiciar a los referidos pueblos y naciones originario indígena campesinas, en la participación de foros y organismos de carácter supranacional de naturaleza indígena ${ }^{100}$, éste se obliga, en virtud de los convenios internacionales anteriormente citados, a tomar medidas apropiadas, incluso por medio de acuerdos internacionales, para facilitar los contactos y la cooperación entre pueblos indígenas y tribales a través de fronteras, incluidas las actividades en las esferas económicas, social, cultural y del medio ambiente ${ }^{101}$.

No obstante, el precepto de referencia, debe entenderse que las Autonomías Originario indígenas Campesinas tienen atribuciones para llevar a cabo actividades en el exterior, en tanto no incidan en la reserva estatal al respecto, y no se deriven de las mismas obligaciones internacionales y responsabilidad internacional del Estado, correspondiendo sólo a éste la celebración de tratados que impliquen tales obligaciones estatales con otros Estados soberanos u organizaciones supranacionales.

TITLE: The autonomic principle in the 2008 bolivian Constitutional text.

AвsтRACT: The 2008 Bolivian Constitutional text proclaims the principle of decentralize and the autonomy principle, to that effect, sets several character that can be object of it, thus belongs to the nations and departments and original rural people the application of the concept of politic autonomy, while the regions, provinces and municipal entities apply the administrative auto-

98 Valga como ejemplo el artículo 26 de la declaración de las Naciones Unidas sobre los derechos de los pueblos indígenas.

99 Artículos 56, 57, 393 y 401.. C.B.

100 Entre los que deben destacarse en el nivel internacional los correspondientes a Naciones Unidas y en el ámbito latinoamericano el Parlamento indígena.

101 Artículo 32 Declaración de las Naciones Unidas sobre los derechos de los pueblos indígenas, y 36 Del Convenio 169 de la OIT. 
nomy. The Constitution, without a full legislative development on the subject and with absence on the constitutional jurisprudence, shown as an open process, unfinished, extremely complex and undetermined, by virtue of the difficult characterization of the autonomy of indigenous communities, which is applicable, not only the constitution and the laws of development, but also the treaties and international agreements about this matter, that the Constitutional text is converted into an internal standard.

RESUMEN: El texto constitucional boliviano de 2008 proclama el principio descentralizador y autonómico; a tal efecto, establece varios sujetos que pueden ser objeto del mismo, así corresponde a los Departamentos y a las Naciones y Pueblos Originario Campesinos la aplicación del concepto de Autonomía política, mientras que a las Regiones, Provincias y entidades municipales les resulta aplicable el de Autonomía administrativa. La Constitución, a falta de desarrollo legislativo sobre el tema y ausencia de jurisprudencia constitucional, se nos presenta como un proceso abierto, inacabado, de suma complejidad e indeterminado, en virtud de la difícil caracterización de la Autonomía de las comunidades indígenas, a las que resulta aplicable, no sólo la Constitución y leyes de desarrollo, sino también los Tratados y Convenios internacionales sobre el tema, que el propio texto constitucional transforma en norma interna.

Key words: Constitution. Autonomy. Nation and Original rural People. Statute. Organic Chart. Free determination. Sovereignty. Legislature.

Palabras claves: Constitución. Autonomía. Nación y Pueblo originario campesino. Estatuto. Carta Orgánica. Libre determinación. Soberanía. Poder constituyente. 